\title{
Development of Action Threshold to Manage Common Leaf Spot and Black Seed Disease of Strawberry Caused by Mycosphaerella fragariae
}

\author{
Odile Carisse $^{1, \dagger}$ and Vanessa McNealis ${ }^{2}$ \\ ${ }^{1}$ Agriculture and Agri-Food Canada, St-Jean-sur-Richelieu, QC, J3B 3E6, Canada; and ${ }^{2}$ Department of Mathematics and Statis- \\ tics, Université de Montréal, Centre-ville Station, Montréal, QC, H3C 3J7, Canada
}

\begin{abstract}
The fungus Mycosphaerella fragariae is responsible for two strawberry diseases: common leaf spot (CLS) and black seed disease (BSD). In June-bearing strawberry plantings, CLS influences vigor, yield, and winter survival. During production years, BSD causes black lesions around strawberry seeds, reducing the market value of the berries. The objective of this study was to characterize the relationships between CLS and BSD and to develop action thresholds for the management of BSD. Data on the number of lesions per leaf, number of black seeds per berry, and percentage of diseased berries were collected at two experimental and six commercial sites from 2000 to 2011, corresponding to 50 farm-years. First, logistic regression was used to model the relationship between BSD occurrence in its binary data form and the number of lesions per leaf assessed at 7, 14, 21, and 28 days before $10 \%$ bloom. Second, linear regression was used to model

the relationship between BSD severity, BSD incidence, and number of lesions per leaf assessed at 7, 14, 21, and 28 days before $10 \%$ bloom. Resulting action thresholds of 15,25 , or 33 lesions per leaf at 21,14 , or 7 days before $10 \%$ bloom, respectively, were compared with the recommended practice at three commercial sites in 2014,2015 , and 2016. The percentage of diseased berries was significantly $(P=0.0016$; least significant difference $=7.140$ ) higher in the sections of the fields that were not managed for BSD, with an average of $15.22 \%$ diseased berries, in comparison with 3.22 and $2.44 \%$ diseased berries in sections managed according to the recommendations and the thresholds, respectively. Overall, $40 \%$ less fungicide was used when the thresholds were applied. Hence, these thresholds can be used as an additional decision tool to optimize fungicide applications during the prebloom period.
\end{abstract}

Common leaf spot (CLS) and black seed disease (BSD) of strawberry are often considered to be two distinct diseases. However, these two diseases are caused by the ascomycete Mycosphaerella fragariae (Tul.) Lindau (= Ramularia tulasnei Sacc.). The perfect stage was described and named Sphaerella fragariae in 1863 by Tulasne and Tulasne (Tulasne and Tulasne 1863). In 1886, Saccardo described the symptoms caused by $R$. tulasnei. However, it was Lindau who, in 1897 , provided the complete taxonomic description and changed the name to Mycosphaerella fragariae (Wilhelm and Nelson 1980). The link between the perfect and the imperfect stages was not established until 1934 by Plakidas (Plakidas 1934). The first studies on diseases caused by $M$. fragariae were conducted in the United States as early as 1885 and 1889 by Trealease and Dudley, respectively (Dudley 1889; Trealease 1885). Since then, these diseases have been reported in most strawberry production areas, from Chile to North America and Siberia (Plakidas 1965). CLS is endemic in most strawberry plantings but is generally considered a disease of secondary importance. However, on susceptible cultivars, when the weather is highly favorable for disease development, CLS can cause important economic losses (Carisse and McNealis 2018). This was the case in strawberry fields in Tennessee, Kentucky, and Michigan in 1957 (Dale and Fulton 1957; Fulton 1958; Janick and Williams 1959; Paulus 1990). Consequently, CLS was considered an important strawberry disease during the 1960s (Plakidas 1965), and resistance to the disease was included in several breeding programs (Janick and Williams 1959; Nemec 1971, 1972). As a result, for almost 30 years, the disease was maintained at a low level by growing strawberry cultivars with resistance or low susceptibility to $M$. fragariae. However, these cultivars were subsequently replaced by

${ }^{\dagger}$ Corresponding author: Odile Carisse; E-mail: odile.carisse@canada.ca

Funding: This work was financially supported by Agriculture and Agri-Food Canada.

Accepted for publication 28 September 2018.

() 2019 The American Phytopathological Society new ones with better yield, storability, color, and flavor but with various degrees of susceptibility to M. fragariae (Carisse and Maas 2005; Nemec 1971).

Symptoms of CLS differ with cultivars, $M$. fragariae races (pathotypes), and weather conditions during infection and lesion development (Bolton 1962; Carisse and Maas 2005; Nemec 1969). Typically, symptoms on leaves first appear on the upper surface as small, circular, purplish red spots. Over time, the spots increase in size and may remain circular or become irregular in shape. As the disease progresses, the spots develop grayish white centers surrounded by purple borders. A high number of lesions per leaf can cause leaf death. Similar symptoms can appear on other aerial plant parts such as berry caps, petioles, and runners. On infected berries, shallow, black spots often surrounded by brown or black leathery tissue will develop. These spots may surround single or groups of seeds (achenes). The pulp under the infected area often becomes discolored, but the berries generally do not decay (Maas 1987). Commonly, one or two spots develop on infected berries, but when conditions are favorable, up to 10 black seeds may develop on a single berry (Carisse and McNealis 2018). Symptoms are most noticeable on white, unripe fruit and on ripe fruit of light-colored cultivars.

There are only a few studies on the economic importance of diseases caused by M. fragariae (Carisse and McNealis 2018; Marcoux 1996). Most losses are owing to the unattractiveness of foliage and of black seed spots on berries, rather than fruit rot. In some strawberry plantings, mainly large ones, the disease may be considered a cosmetic problem that has little impact on fruit yield or quality. However, fruits with black seeds are generally not harvested. For strawberry producers using pick-your-own harvesting, fruit damage (black seed spots) translates into direct losses when customers do not pick berries with black seeds. Marcoux (1996) studied the effect of $M$. fragariae on strawberry leaf photosynthesis and fruit yield and reported a significant reduction in photosynthesis when the percentage of leaf area diseased was above $16 \%$. In unsprayed plots under field conditions, Marcoux (1996) observed a reduction of up to $13.0 \%$ in berry weight and an increase of up to $48.7 \%$ in the percentage of diseased berries. Recently, Carisse and McNealis (2018) reported that in the province of Quebec, in Eastern Canada, BSD was present in $40 \%$ of strawberry fields ( $n=186$ fields). 
CLS and BSD are managed mostly by using disease-free plants and growing cultivars with low or moderate susceptibility (Delhomez et al. 1995; Nemec 1971). For June-bearing cultivars, nitrogen fertilization should be reduced at renovation to diminish the abundance of tender new leaf tissue, which is highly susceptible (Carisse et al. 2000). Because a prolonged period of leaf wetness is required for infection and sporulation (Carisse and Peyrachon 1999; Carisse et al. 2000; Elliott 1988), air circulation should be promoted by optimal spacing of runner plants in a matted-row system and by good control of weeds. If CLS is present during the planting year, applying protective fungicides is recommended (CRAAQ 2013; OMAFRA 2016). Some protection guides recommend protecting new leaves as they unfold (OMAFRA 2016). Other guides recommend applying, during the production years, a fungicide once or twice in early spring if more than 25 or $50 \%$ of the leaves, respectively, were infected during the previous fall (CRAAQ 2013). The Quebec strawberry pest management guide (CRAAQ 2013) recommends initiating the fungicide spray program when the disease is "established" or has reached $5 \%$ and to perform a subsequent fungicide application at a 7 - to 14-day interval. In the absence of information on disease intensity, a fungicide application is recommended at the beginning of bloom (CRAAQ 2013; OMAFRA 2016). Growers who are risk-averse tend to overspray against CLS, whereas some growers do not manage CLS or BSD, because the economic benefits of doing so are unclear. Considering the cost of fungicides, their impact on the environment, the increasing problem of fungicide resistance, and consumer demand for fruits free of pesticide residues, it is important to use fungicides only when needed (Gossen et al. 2014).

Action thresholds for timing fungicide applications can be used to optimize fungicides for the management of both CLS and BSD. Because the disease first develops on leaves, we hypothesized that there is a leaf disease level that can be used as an action threshold for fungicide applications to prevent or limit berry damage. Hence, our first objective was to investigate the relationship between CLS and BSD. This was achieved using (i) logistic regressions to model the relationship between the occurrence of BSD and CLS severity expressed as the number of lesions per strawberry leaf, and (ii) linear regressions to model the relationship between the number of black seeds per fruit (BSD severity) and CLS severity and between the percentage of diseased berries (BSD incidence) and CLS severity. Because the objective was to establish action thresholds, analyses were conducted using the number of lesions per leaf assessed at 7, 14, 21, and 28 days before $10 \%$ bloom. The second objective was to evaluate these action thresholds for prebloom management of BSD.

\section{Materials and Methods}

Field sampling. Field sampling was previously described in Carisse and McNealis (2018), so only a brief description is given here. Both CLS and BSD were monitored from 2000 to 2011, corresponding to 50 farm-years, for a total of 186 fields (not all fields were assessed every year) (Table 1). The fields, each 0.5 to 1.0 ha, were located in Quebec, Canada, on the Agriculture and Agri-Food Canada experimental farms in l'Acadie and Frelighsburg and on

Table 1. Description of the data used to develop the thresholds

\begin{tabular}{lccccc}
\hline Sampling & $\begin{array}{c}\text { Number } \\
\text { of fields } \\
\text { sampled }\end{array}$ & $\begin{array}{c}\text { Total } \\
\text { number of } \\
\text { fields } \\
\text { sampled }\end{array}$ & $\begin{array}{c}\text { Number } \\
\text { of fields } \\
\text { with BSD }\end{array}$ & $\begin{array}{c}\text { Mean } \\
\text { number of } \\
\text { CLS lesion } \\
\text { per leaf }\end{array}$ \\
\hline EXP 1 & $2000-2011$ & 3 & 36 & 21 & 25.5 \\
STF & $2006-2010$ & 3 & 15 & 0 & 1.8 \\
STP & $2006-2010$ & 5 & 25 & 5 & 22.3 \\
BEAM & $2007-2008$ & 5 & 10 & 0 & 2.50 \\
RODM & 2008 & 5 & 5 & 0 & 0 \\
GAUB & $2008-2009$ & 5 & 10 & 5 & 9.9 \\
STH & $2000-2011$ & 3 or 5 & 52 & 30 & 23.1 \\
EXP 2 & $2000-2011$ & 3 & 33 & 12 & 17.3 \\
\hline
\end{tabular}

${ }^{\mathrm{a}} \mathrm{BSD}=$ black seed disease.

${ }^{\mathrm{b}} \mathrm{CLS}=$ common leaf spot. commercial farms located in the Montérégie strawberry production area, which is southeast of Montreal. Data were collected in Junebearing plantings with the cultivars Chambly, Kent, and Jewel during the first or second year of production. In each field, from bud break to the end of harvest, the number of leaf spots was assessed on the five youngest fully expanded leaves of 25 plants twice weekly. At each sampling, plants were selected randomly. Because it is easier to detect black seeds when the fruits are not completely red, the number of black seed spots per berry was assessed 2 weeks before the first harvest on 100 randomly selected berries . To facilitate the comparison of data collected during several years, at different locations, and on different cultivars, sampling dates were expressed as days before $10 \%$ bloom.

Relationship between occurrence of BSD and CLS. First, the data set was split into training and validation subsets using an 80: 20 ratio with PROC SURVEYSELECT in the SAS software program (version 9.4; SAS Institute, Cary, NC). In most instances, BSD is not present and thus there are not required management actions; hence, we first looked at the occurrence of BSD in relation to CLS. Because BSD occurrences are binary data (presence or absence of BSD) and severity of CLS was expressed as the number of lesions per leaf, logistic regression was used to model the relationship between BSD and CLS according to the following equation:

$$
\ln \left[\frac{p(\boldsymbol{x})}{1-p(\boldsymbol{x})}\right]=\alpha+\beta \mathrm{CLS}
$$

where CLS is the number of CLS lesions per leaf assessed at 7, 14, 21 , and 28 days before $10 \%$ bloom; $p(x)$ is the probability of observing BSD, which depends on the values of regressor CLS; $\alpha$ is the intercept parameter (the value of $\ln \{p(x) /[1-p(x)]\}$ when $x=0$ ); and $\beta$ is the slope parameter of the logistic model (Weisberg 2014). The logistic analysis was conducted using PROC LOGISTIC in the SAS software program. A logistic model was used to predict the probability of BSD occurrence [ $p(x)$ in equation 1]. To classify a field-year as an occurrence of BSD, we used a probability $\left(p_{c}\right)$ threshold so that an occurrence of BSD was predicted when the probability $p(x)$ was greater than 0.5 . Logistic regressions were conducted for the number of lesions per leaf assessed at 7, 14, 21, and 28 days before $10 \%$ bloom. The data not used to develop the models were used for validation.

Modeling BSD incidence and severity. BSD data were expressed as the number of black seeds per berry (severity) and the percentage of diseased berries (incidence). Only data with positive occurrence of BSD were analyzed. On the basis of preliminary observations of the distribution of both BSD severity and incidence as a function of the

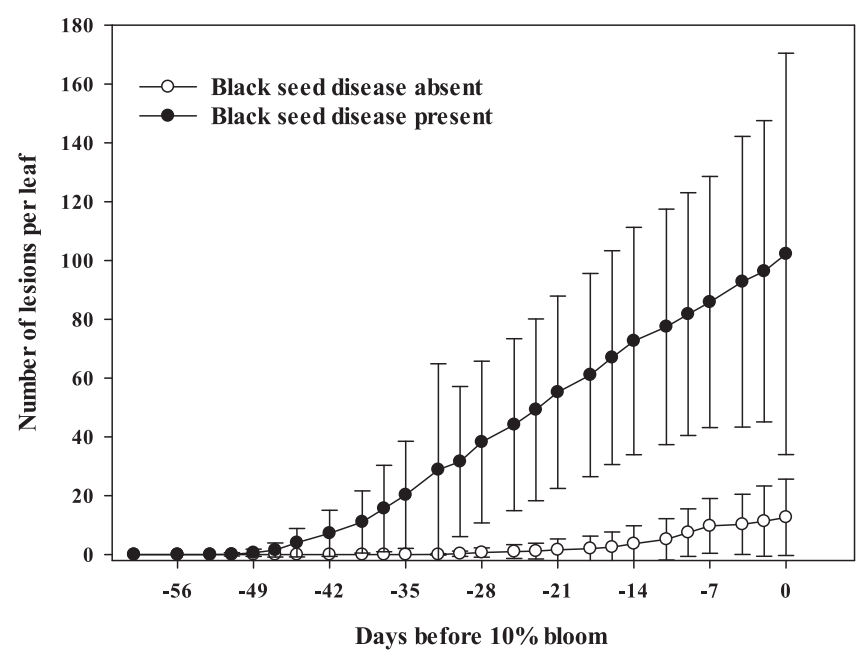

Fig. 1. Temporal progress of common leaf spot in fields where black seed disease was absent (empty circles) or present (filled circles). Observations are from 186 fields from 2000 to 2011. Both diseases are caused by Mycosphaerella fragariae. 
number of lesions per leaf, linear regression was used for modeling purposes, as follows:

$$
\mathrm{BSD}=\beta_{0}+\beta_{1} \mathrm{CLS}+e
$$

where BSD is either predicted severity or predicted incidence, $\beta_{0}$ is the intercept, $\beta_{1}$ is the slope, CLS is the number of CLS lesions per leaf assessed at 7, 14, 21, and 28 days before $10 \%$ bloom, and $e$ is the residual. The models were evaluated based on the $R^{2}$ value and the concordance correlation coefficient, calculated as $r \times \mathrm{C}_{\mathrm{b}}$, where $r$ is the Pearson product-moment correlation between observed and predicted BSD and $\mathrm{C}_{\mathrm{b}}$ is a bias coefficient. The data not used to develop the models were used for validation (Madden et al. 2007).

Evaluation of the disease-based thresholds for prebloom management of BSD. To evaluate the need for prebloom fungicide applications for the management of BSD, leaf-disease-based thresholds were evaluated from 2014 to 2016 on three commercial farms located in the Montérégie strawberry production area. The fields were planted with a June-bearing cultivar, either Chambly or Jewel. Disease data were collected in fields that were in the first or second year of production, as described above. The number of leaf spots per leaf (on the five youngest fully expanded leaves) was assessed weekly, from bud break to the last harvest, on 25 plants that were randomly selected per field section at each sampling. BSD was assessed as described above. On all farms, the rows were spaced $1.2 \mathrm{~m}$ apart, and within rows, the plants were spaced $30 \mathrm{~cm}$ apart. On each farm, 0.30- to 0.45 -ha strawberry fields were allocated for the experiments. The entire fields were managed for gray mold (Botrytis cinerea) by applying a fungicide one to three times at the growth stages of 10 , 50 , and $80 \%$ bloom. The number of fungicide applications against gray mold was determined based on frequency of rain during the flowering period. The fungicides used during flowering were boscalid/pyraclostrobin (Pristine WG at a rate of $1.4 \mathrm{~kg} / \mathrm{ha}$ ), fenhexamid (Elevate $50 \mathrm{WDG}$ at a rate of $1.7 \mathrm{~kg} / \mathrm{ha}$ ), pyrimethanil (Scala SC at a rate of 2.0 liters/ha), or iprodione (Rovral at a rate of $2.0 \mathrm{~kg} / \mathrm{ha}$ ). Each field was divided in three sections of equal size. In one section, BSD was not managed. In another section, a fungicide was applied before the next forecasted rainfall of greater than $10 \mathrm{~mm}$, if the number of lesions per leaf at 21,14 , or 7 days before $10 \%$ bloom was 15 , 25 , or 33 , respectively. In the third section, fungicides were applied according to the provincial recommendations every 7 to 14 days
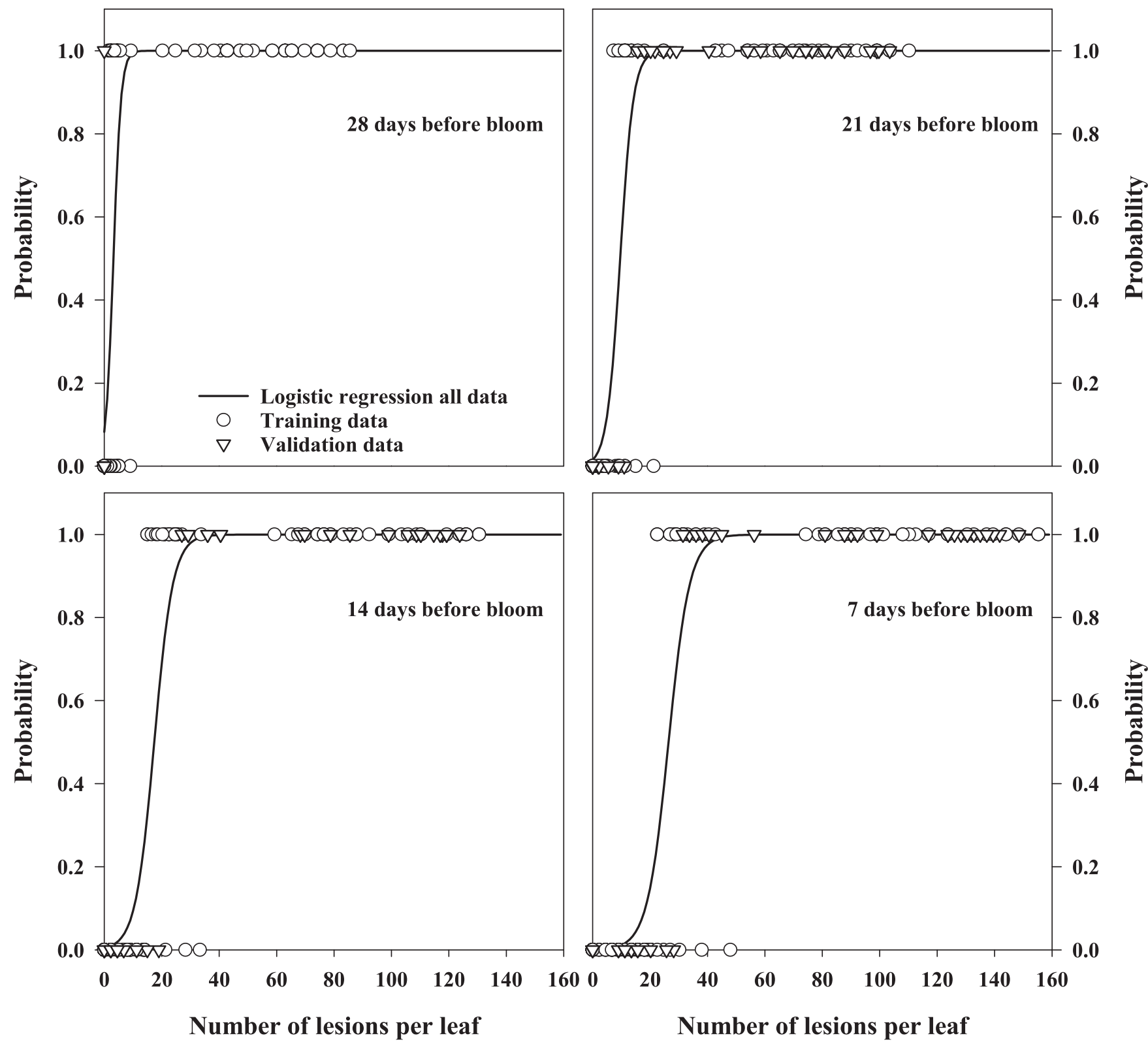

Fig. 2. Relationship between the probability of black seed disease occurrence and the number of lesions per leaf. The curve plotted is $p=1 /\left[1+\exp \left(-\alpha-\beta_{1} \mathrm{CLS}\right)\right]$, where $p$ is the probability of black seed disease occurrence, represented on the vertical axis, $\alpha$ and $\beta_{1}$ are estimated coefficients for logistic models (Table 2), and CLS is the number of lesions per leaf assessed at 7, 14, 21, and 28 days before $10 \%$ bloom. 
Table 2. Estimated parameters and corresponding standard errors (in parentheses) of logistic models (equation 1) used to classify field-years for occurrence of black seed disease (Mycosphaerella fragariae), prediction accuracy, sensitivity, and specificity

\begin{tabular}{|c|c|c|c|c|c|c|c|c|}
\hline \multirow[b]{2}{*}{ Variables $^{\mathbf{a}}$} & \multicolumn{2}{|c|}{$\begin{array}{l}\text { Estimated regression parameters } \\
\text { (standard errors) }^{\mathbf{b}}\end{array}$} & \multicolumn{2}{|c|}{$\begin{array}{c}\text { Prediction } \\
\text { accuracy }(\%)^{\mathbf{c}}\end{array}$} & \multicolumn{2}{|c|}{ Sensitivity $(\%)^{d}$} & \multicolumn{2}{|c|}{ Specificity $(\%)^{\mathrm{e}}$} \\
\hline & $\alpha$ & $\beta_{1}$ & $\mathbf{T}$ & $\mathbf{V}$ & $\mathbf{T}$ & $\mathbf{V}$ & $\mathbf{T}$ & $\mathbf{V}$ \\
\hline 7 days before bloom, training & $-6.7181(1.4093)$ & $0.2454(0.0545)$ & 95.1 & 95.2 & 92.3 & 96.1 & 96.7 & 93.7 \\
\hline 7 days before bloom, all & $-7.4443(1.4553)$ & $0.2708(0.0542)$ & 95.7 & $\ldots$ & 94.9 & $\ldots$ & 96.3 & $\ldots$ \\
\hline 14 days before bloom, training & $-5.2461(1.0776)$ & $0.2925(0.0616)$ & 95.8 & 92.9 & 94.2 & 92.3 & 96.4 & 93.7 \\
\hline 14 days before bloom, all & $-5.6412(1.1027)$ & $0.3066(0.0606)$ & 95.7 & $\ldots$ & 94.8 & $\ldots$ & 96.3 & $\ldots$ \\
\hline 21 days before bloom, training & $-4.3331(0.8510)$ & $0.4201(0.0881)$ & 94.4 & 90.5 & 92.3 & 92.3 & 95.6 & 93.7 \\
\hline 21 days before bloom, all & $-4.6133(0.8655)$ & $0.4346(0.0861)$ & 94.6 & $\ldots$ & 93.6 & $\ldots$ & 95.3 & $\ldots$ \\
\hline 28 days before bloom, training & $-3.0053(0.4896)$ & $0.7610(0.1601)$ & 88.2 & 88.1 & 80.8 & 88.5 & 93.4 & 87.5 \\
\hline 28 days before bloom, all & $-3.1682(0.4775)$ & $0.7597(0.1402)$ & 90.3 & $\ldots$ & 87.2 & $\ldots$ & 92.6 & \\
\hline
\end{tabular}

${ }^{a}$ Logistic regression models were developed using the training data set and the complete data set (all). The probability of a greater $\chi^{2}$ for a score test was $P<$ 0.0001 for all models.

${ }^{\mathrm{b}}$ In accordance with equation 1, estimates of the parameters $\alpha$ (the intercept parameter) and $\beta$ (the coefficient parameter) for the number of lesions per leaf at 28 , 21,14 , and 7 days before bloom.

${ }^{\mathrm{c}}$ Prediction accuracy as a percentage of correctly classified cases of occurrence and nonoccurrence (outbreak $=$ at least one case of black seed disease). $\mathrm{T}$ and $\mathrm{V}$ represent the training and validation, respectively.

d Sensitivity as a percentage of correctly classified outbreaks. An observation was classified as an outbreak if predicted probability $p(x)(e q u a t i o n ~ 1)$ was greater than 0.5 .

e Specificity, as a percentage of correctly classified non-outbreaks. An observation was classified as a non-outbreak if predicted probability $p(x)$ (equation 1$)$ was greater than 0.5 .
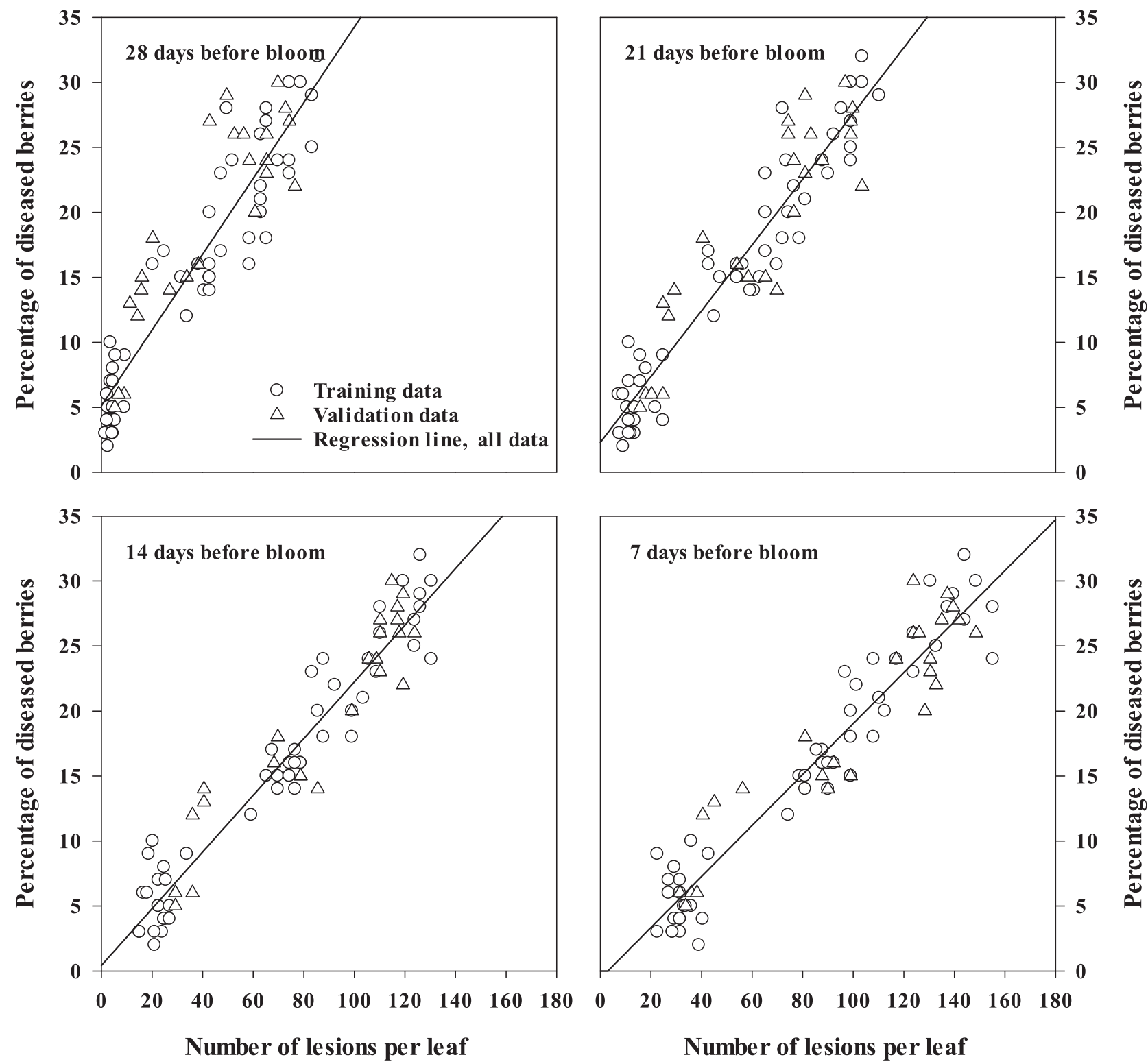

Fig. 3. Relationship between the observed and predicted percentages of diseased berries and numbers of lesions per leaf assessed at $28,21,14$, and 7 days before $10 \%$ bloom. Data were collected from 2000 to 2011, and predicted values were calculated using equation 2 and the estimated parameters presented in Table 2. 
starting when lead disease (CLS) incidence reached 5\% diseased leaves. The fungicide used to manage BSD was captan (Maestro $80 \mathrm{DF}$ at a rate of 2.8 to $4.2 \mathrm{~kg} / \mathrm{ha}$ ).

\section{Results}

In fields where BSD was not observed, the number of lesions per leaf remained low, reaching on average only 12.7 lesions per leaf at bloom, whereas in fields where BSD was present, the number of lesions per leaf increased gradually to reach on average 102.3 lesions per leaf at bloom (Fig. 1). A large variation in the number of lesions per leaf was observed in fields where BSD was present. However, good separation between occurrence and nonoccurrence of BSD on the basis of the number of lesions per leaf was observed about 30 days before $10 \%$ bloom. This was supported by the logistic regressions (Fig. 2). When the logistic models were applied to the training data set, their prediction accuracy ranged from 88.2 to $95.8 \%$ (Table 2). All models significantly $(P<0.05)$ predicted occurrence and nonoccurrence regardless of the leaf disease assessment time $(7,14,21$, or 28 days before bloom). The models developed with the training data set were used to calculate the sensitivity, specificity, and overall accuracy for the validation data (not used to develop the model) (Table 2). Because the models developed with the training data accurately fitted both the training data and the validation data, another set of logistic regressions was conducted using all data (training and validation data). On the basis of parameters of the logistic regression calculated using all data (Table 2) and a critical probability of $p_{c}=0.50$, the numbers of lesions per leaf of 27.5, 18.4, 10.6, and 4.2 assessed at $7,14,21$, and 28 days before $10 \%$ bloom, respectively, indicated an occurrence of BSD (Fig. 2).

Regardless of the leaf disease assessment time, there was a linear relationship between the number of lesions per leaf and both the incidence and the severity of BSD, expressed as the percentage of diseased berries and the number of black seeds per berry, respectively (Figs. 3 and 4, Tables 3 and 4). As was the case for the logistic regression, the models developed with the training data accurately fitted both the training data and the validation data (Tables 3 and 4). However, there was a trend of decreasing reliability with increasing time between CLS assessment and 10\% bloom (Tables 3 and 4). Nevertheless, another set of linear regressions was conducted using all data (training and validation data) and was used to predict BSD incidence
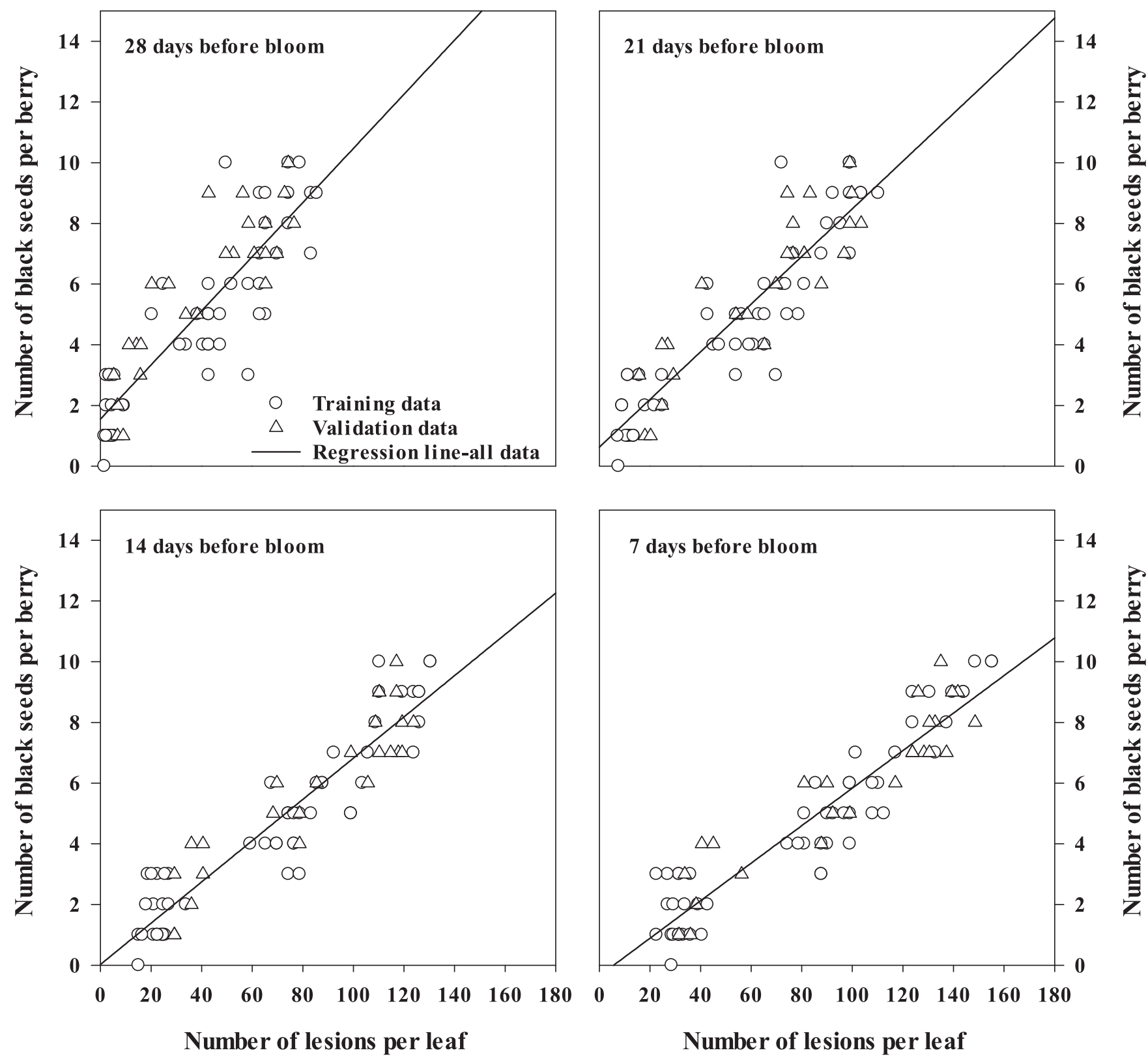

Fig. 4. Relationship between the observed and predicted numbers of black seeds per berry and numbers of lesions per leaf assessed at $28,21,14$, and 7 days before $10 \%$ bloom. Data were collected from 2000 to 2011, and predicted values were calculated using equation 2 and the estimated parameters presented in Table 3. 
and severity based on the number of lesions per leaf. Assuming that $5 \%$ diseased berries is acceptable, the model predicted a threshold of $0,11,21$, and 28 lesions per leaf assessed at 28, 21, 14, and 7 days before bloom, respectively (Table 3, Fig. 3). Similarly, assuming a tolerance level of no more than one black seed per berry, the model predicted a threshold of 4, 18, 29, and 38 lesions per leaf assessed at 28, 21, 14, and 7 days before bloom, respectively (Table 4, Fig. 4). Consequently, considering both disease tolerance levels of $5 \%$ diseased berries and one black seed per berry, the thresholds for BSD management are 2, 15, 25, and 33 lesions per leaf, assessed at 28, 21,14 , and 7 days before bloom, respectively.

In 2014, the average rainfall in May was $170.0 \mathrm{~mm}(164.0,168.9$, and $177.2 \mathrm{~mm}$ at sites 1,2 , and 3, respectively). In 2015, the average rainfall in May was $139.33 \mathrm{~mm}(195.6,102.4$, and $120.0 \mathrm{~mm}$ at sites 1,2 , and 3, respectively). In 2016, the average rainfall in May was $68.33 \mathrm{~mm}$ (78.9, 73.2, and $52.9 \mathrm{~mm}$ at sites 1,2 , and 3, respectively). Overall, for the three years, the percentage of diseased berries was significantly $(P=0.0016$; least significant difference $=7.142)$ higher in the sections of the strawberry fields that were not managed for BSD, with a mean (over years and sites) of $15.22 \%$ diseased berries, in comparison with 2.44 and $3.22 \%$ diseased berries in the sections managed on the basis of thresholds and provincial recommendations, respectively (Fig. 5). In the sections of the strawberry fields not managed for BSD, the percentage of diseased berries was 24.33, 21.33, and $0.00 \%$ in 2014,2015 , and 2016, respectively, whereas in the sections managed for BSD on the basis of thresholds and recommendations, it was $4.33,3.00$, and $0.00 \%$ and $5.00,4.67$, and $0.00 \%$ in 2014, 2015, and 2016, respectively (Fig. 6).

When BSD was managed using leaf-disease thresholds, for the three years and the three sites, BSD was maintained at or below $5 \%$ diseased berries, with an average of $1.33,1.0$, and 0.0 fungicide applications in 2014, 2015, and 2016, respectively (Fig. 6). When leaf disease was managed with fungicide application at 7 to 14 days starting when leaf disease (CLS) incidence reached 5\%, BSD was also maintained close to or below $5 \%$ diseased berries, with an average of 2.0, 1.7, and 0.3 fungicide applications in 2014, 2015, and 2016, respectively (Fig. 6).

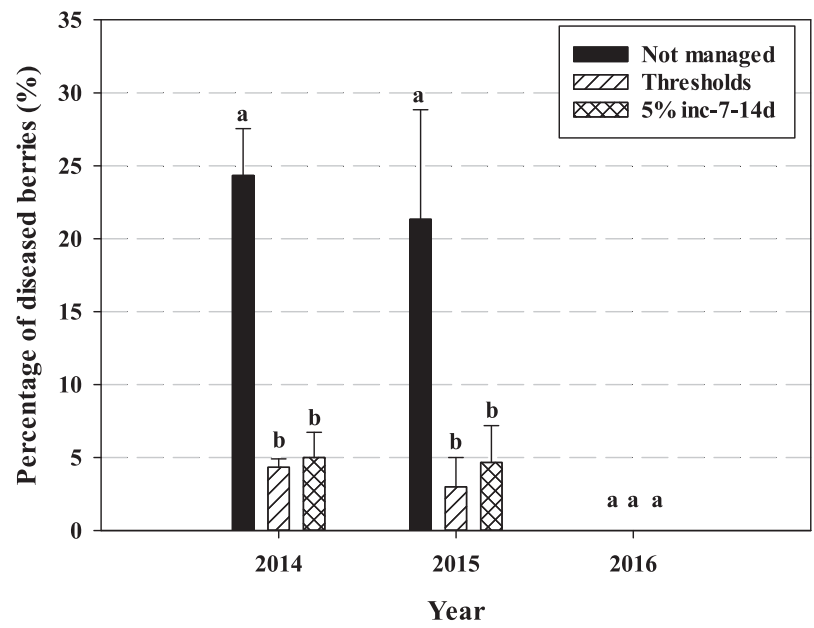

Fig. 5. Percentage of diseased berries at harvest in strawberry fields not managed for black seed disease, strawberry fields managed using leaf-disease-based thresholds, and strawberry fields managed on the basis of a $5 \%$ incidence for initiation and a 7 - to 14-day interval. Values are averaged over three sites, and within each year, values of bars with the same letters are not significantly different at the 0.05 level based on a least significant difference test.

Table 3. Estimated parameters for linear models predicting the incidence of black seed disease (percentage of diseased berries) as a function of the number of lesions per leaf assessed at 7,14,21, and 28 days before bloom

\begin{tabular}{|c|c|c|c|c|}
\hline \multirow[b]{2}{*}{ Variables $^{\mathbf{a}}$} & \multicolumn{2}{|c|}{$\begin{array}{l}\text { Estimated regression parameters } \\
\text { (corresponding standard errors) }^{\mathbf{b}}\end{array}$} & \multirow[b]{2}{*}{$R^{2}, \mathrm{c}$ training (validation) } & \multirow[b]{2}{*}{ CCC, ${ }^{\mathrm{d}}$ training (validation) } \\
\hline & $\boldsymbol{\beta}_{0}$ & $\beta_{1}$ & & \\
\hline 7 days before bloom, training & $-1.0201(0.7577)$ & $0.2003(0.0083)$ & $0.92(0.89)$ & $0.95(0.91)$ \\
\hline 7 days before bloom, all & $-0.5826(0.6703)$ & $0.1962(0.0070)$ & 0.91 & 0.93 \\
\hline 14 days before bloom, training & $0.3737(0.6577)$ & $0.2181(0.0084)$ & $0.93(0.90)$ & $0.96(0.93)$ \\
\hline 14 days before bloom, all & $0.5257(0.0137)$ & $0.0258(0.0014)$ & 0.89 & 0.94 \\
\hline 21 days before bloom, training & $2.0902(0.06636)$ & $0.2529(0.0107)$ & $0.83(0.82)$ & $0.95(0.73)$ \\
\hline 21 days before bloom, all & $2.3050(0.6545)$ & $0.2531(0.0102)$ & 0.89 & 0.88 \\
\hline 28 days before bloom, training & $4.6026(0.7143)$ & $0.2908(0.0154)$ & $0.87(0.74)$ & $0.93(0.37)$ \\
\hline 28 days before bloom, all & $5.1197(0.7036)$ & $0.2915(0.0150)$ & 0.83 & 0.75 \\
\hline
\end{tabular}

${ }^{a}$ Linear regression models were developed using observations from fields where black seed disease was present (59 field observations).

${ }^{\mathrm{b}}$ Estimates of the intercept parameter $\beta_{0}$ and the slope parameter $\beta_{1}$ (equation 2) and corresponding standard errors (in parentheses).

${ }^{c}$ Pearson product-moment correlation between observed and predicted percentages of diseased berries.

${ }^{\mathrm{d}}$ Concordance correlation coefficient (CCC) between observed and predicted percentages of diseased berries.

Table 4. Estimated parameters for linear models predicting the severity of black seed disease (number of black seeds per berry) as a function of the number of lesions per leaf assessed at 7, 14, 21, and 28 days before bloom

\begin{tabular}{|c|c|c|c|c|}
\hline \multirow[b]{2}{*}{ Variables $^{\mathbf{a}}$} & \multicolumn{2}{|c|}{$\begin{array}{l}\text { Estimated regression parameters } \\
\text { (corresponding standard errors) }^{\text {b }}\end{array}$} & \multirow[b]{2}{*}{$R^{2}, \mathrm{c}$ training (validation) } & \multirow[b]{2}{*}{ CCC, ${ }^{\mathrm{d}}$ training (validation) } \\
\hline & $\beta_{0}$ & $\beta_{1}$ & & \\
\hline 7 days before bloom, training & $-0.5195(0.3020)$ & $0.0630(0.0033)$ & $0.88(0.87)$ & $0.93(0.91)$ \\
\hline 7 days before bloom, all & $-0.3488(0.2549)$ & $0.0618(0.0027)$ & 0.87 & 0.84 \\
\hline 14 days before bloom, training & $0.0307(0.2923)$ & $0.0679(0.0037)$ & $0.87(0.85)$ & $0.92(0.91)$ \\
\hline 14 days before bloom, all & $0.0244(0.2449)$ & $0.0679(0.0030)$ & 0.86 & 0.83 \\
\hline 21 days before bloom, training & $0.5503(0.3003)$ & $0.0779(0.0049)$ & $0.84(0.80)$ & $0.91(0.84)$ \\
\hline 21 days before bloom, all & $0.6287(0.2617)$ & $0.0785(0.0041)$ & 0.82 & 0.90 \\
\hline 28 days before bloom, training & $1.3852(0.3142)$ & $0.0878(0.0068)$ & $0.77(0.73)$ & $0.87(0.69)$ \\
\hline 28 days before bloom, all & $1.5512(0.2742)$ & $0.0892(0.0058)$ & 0.75 & 0.86 \\
\hline
\end{tabular}

${ }^{a}$ Linear regression models were developed using observations from fields where black seed disease was present (59 field observations).

${ }^{\mathrm{b}}$ Estimates of the intercept parameter $\beta_{0}$ and the slope parameter $\beta_{1}$ (equation 2) and corresponding standard errors (in parentheses).

${ }^{\mathrm{c}}$ Pearson product-moment correlation between observed and predicted numbers of black seeds per berry.

${ }^{\mathrm{d}}$ Concordance correlation coefficient (CCC) between observed and predicted numbers of black seeds per berry. 


\section{Discussion}

For strawberry growers, disease management decisions are part of a large array of decisions required for producing and selling strawberries. In addition, disease management decisions related to leaf diseases are generally not the main concern, because several other diseases affecting berries are also present (Carisse and Maas 2005). In Eastern Canada, disease management programs generally target gray mold caused by $B$. cinerea, powdery mildew caused by Podosphaera aphanis, and anthracnose caused by Colletotrichum fragariae, C. acutatum, and C. gloeosporioides. Also, there is an assumption that fungicides used to manage these diseases will control leaf diseases and that there is no need for specific sprays to manage leaf spot. It is only recently that accurate information about crop losses caused by $M$. fragariae has been available (Carisse and McNealis 2018). The primary objective of the present study was to develop and evaluate leaf disease action thresholds for prebloom management of BSD.

Growers need precise information about losses to plan decisions for determining when control measures should be used. In this case, we are referring mostly to within-season decisions such as applying fungicides. Using thresholds for disease management decisions is the foundation of rational disease management and should help reduce wrong decisions, such as applying a fungicide when it was not necessary or not applying a fungicide when it was necessary. Several types of thresholds are used for disease management, and they are described in detail by Nutter et al. (1993). An action threshold is defined as the pathogen population density or injury level at which action must be taken to prevent the disease from exceeding the damage threshold, which is defined by the grower's production objectives. An economic threshold is defined as the injury level above which the cost of damage if no action is taken will exceed the cost of action (e.g., fungicide application). A warning threshold is the pathogen population density or injury level below the action threshold and warns growers to be prepared for action. In this study, our intention was to develop action thresholds. When using a threshold approach for disease management decision making, it is assumed that the threshold is a reliable predictor of damage and is established in such way that growers have enough time to take actions such as applying a fungicide. The thresholds developed in this study meet these criteria because a good relationship was observed between leaf and berry damage, and leaf damage occurs a few weeks before the optimum time for fungicide applications. First, logistic regression was used to determine the critical number of lesions per leaf that allows discrimination between occurrence and nonoccurrence of BSD. From this analysis, thresholds of 27.5, 18.4, 10.6, and 4.2 lesions per leaf assessed at 7, 14, 21, and 28 days before bloom, respectively, were established (Fig. 2). The highest accuracy was obtained when the number of lesions per leaf was assessed at a maximum of 21 days before bloom, with overall accuracy of 95.0, 95.8, and 94.6\% for assessments made 7, 14, and 21 days before bloom, respectively. The overall accuracy dropped to $90.3 \%$ when the number of lesions per leaf was assessed at 28 days before bloom.

There are no damage thresholds for BSD, and it is expected that thresholds will vary according to the type of harvesting and marketing. Growers practicing pick-your-own harvesting should probably not tolerate more than $5 \%$ diseased berries, which, according to our results, corresponds to thresholds of $0,11,21$, and 28 lesions per leaf assessed at 28, 21, 14, and 7 days before bloom, respectively (Figs. 3 and 4). Acceptable injury levels will vary depending on the grower, but if we consider an injury level of one black seed per berry, that corresponds to thresholds of 4, 18, 29, and 38 lesions per leaf assessed at 28, 21, 14, and 7 days before bloom, respectively (Figs. 3 and 4). Nevertheless, the models predicting the percentage of diseased berries and the number of black seeds per berry can be used to calculate thresholds on the basis of various damage and injury levels.

In this study, all analyses were conducted using the number of lesions per leaf assessed at 28,21, 14, and 7 days before bloom to anticipate the risk of BSD as early as possible so that management actions can be combined with other actions required to manage gray mold, powdery mildew, and anthracnose. In general, better accuracy and reliability were obtained when the number of lesions per leaf was assessed within 21 days before bloom, which should provide enough time for the grower to decide whether a specific treatment for controlling black seed is needed. When these thresholds were evaluated on three commercial strawberry farms, BSD was maintained at under $5 \%$ diseased berries with 1.2 fungicide applications on average (2014 and 2015), as opposed to 1.8 applications when the provincial recommendations were followed. Many growers are hesitant to apply fungicides to control CLS prior to bloom because the economic benefits of doing so are uncertain. In this study, we observed 24.33, 21.33 , and $0.00 \%$ diseased berries in 2014, 2015, and 2016, respectively. The average rainfall in May was 170.0, 139.33, and $68.33 \mathrm{~mm}$ in 2014, 2015, and 2016, respectively. These data suggest that, during wet springs and in the absence of prebloom CLS control, BSD can reduce yield considerably. Disease-based threshold use requires that information on the disease level be collected. In the province of Quebec, most strawberry growers have access to scouting services. Leaf spots have a typical appearance, and hence scouting is fast and reliable (Turechek and Madden 2000). In this study, thresholds were developed based on the most commonly used sampling size of 25 plants per field. However, it might be possible to further facilitate scouting by determining the relationship between CLS incidence (presence or absence of lesions) and severity (number of lesions per leaf) (Carisse et al. 2013). However, to efficiently use
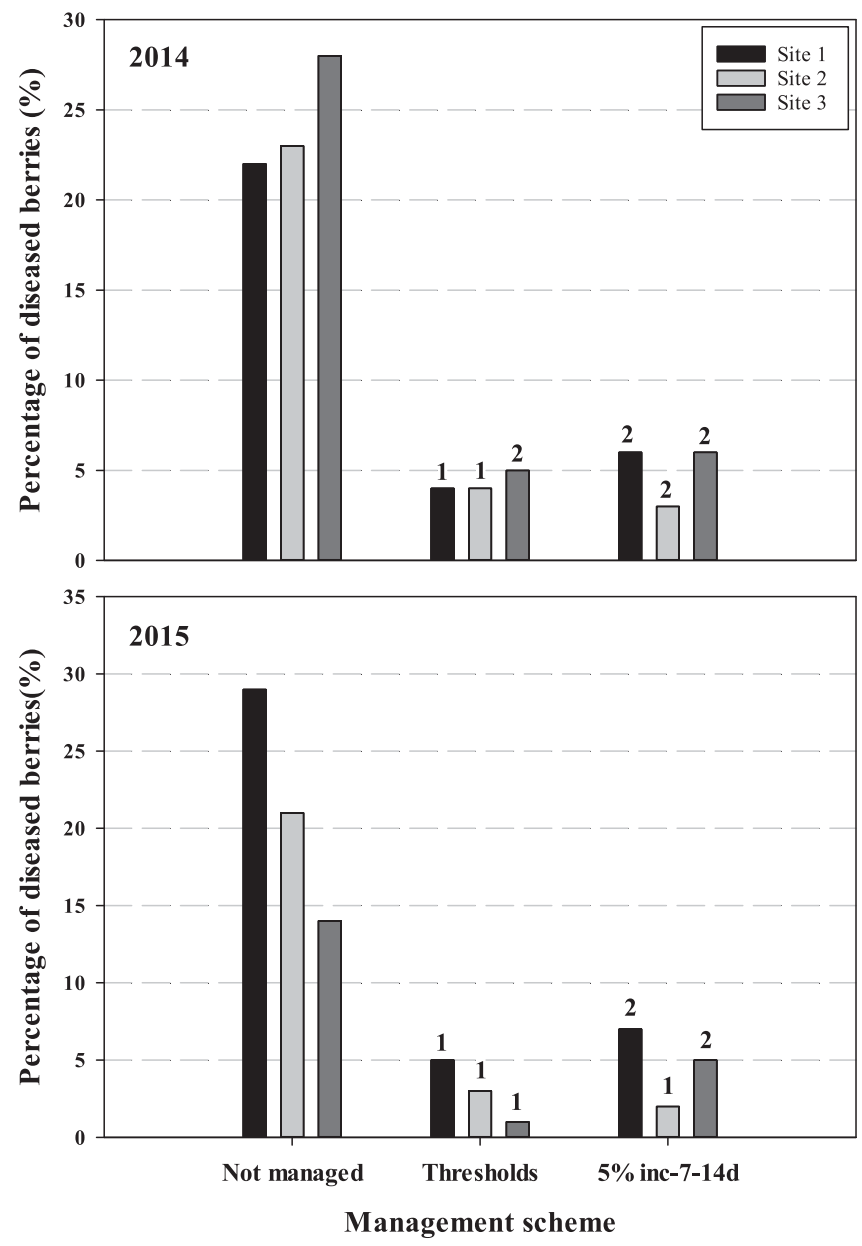

Fig. 6. Percentage of diseased berries at harvest in strawberry fields not managed for black seed disease, strawberry fields managed using leaf-disease-based thresholds, and strawberry fields managed on the basis of a $5 \%$ incidence for initiation and a 7 - to 14-day interval. The values above the bars represent the number of fungicide applications. No black seed disease developed in 2016. However, one fungicide application was carried out at one site in the field managed on the basis of a $5 \%$ incidence for initiation and a 7- to 14-day interval. 
these thresholds, growers must forecast the beginning of the flowering period. CLS and BSD are important mostly on June-bearing strawberry cultivars during production years (2- and 3-year old plantings). Beginning of bloom can be predicted based on cultivars (early or late bearing), degree-day models, and grower's experience (Schwartz 2013). Most growers monitor strawberry growth for pest management but also to predict harvesting period. Nevertheless, information on phenological stage is available on several integrated pest management and phytosanitary warning websites (Plouffe et al. 2014). These leaf-disease-based thresholds could be combined with the amount of rain in May (Carisse and McNealis 2018) to anticipate the need for prebloom fungicide sprays and avoid unnecessary fungicide applications, reducing the costs and environmental impact of strawberry production.

\section{Acknowledgments}

The authors are grateful to Annie Lefebvre and Daniel Rolland for their technical assistance and to the strawberry growers who allowed us to collect data on their farms.

\section{Literature Cited}

Bolton, A. T. 1962. Pathogenic variation in Mycosphaerella fragariae. Can. J. Bot. 40:647-650.

Carisse, O., Bourgeois, G., and Duthie, J. A. 2000. Influence of temperature and leaf wetness duration on infection of strawberry leaves by Mycosphaerella fragariae. Phytopathology 90:1120-1125.

Carisse, O., Lefebvre, A., Van der Heyden, H., Roberge, L., and Brodeur, L. 2013. Analysis of incidence-severity relationships for strawberry powdery mildew as influenced by cultivar, cultivar type, and production systems. Plant Dis. 97: 354-362.

Carisse, O., and Maas, J. 2005. Strawberry diseases/Les maladies du fraisier. Pages 98-117 in: Our Strawberries/Les fraises de chez nous. S. Khanizadeh and J. DeEll, eds. Government of Canada, Ottawa, ON.

Carisse, O., and McNealis, V. 2018. Identification of weather conditions associated with the occurrence, severity, and incidence of black seed disease of strawberry caused by Mycosphaerella fragariae. Phytopathology 108:83-93.

Carisse, O., and Peyrachon, B. 1999. Influence of temperature, cultivar, and time on sporulation of Mycosphaerella fragariae on detached strawberry leaves. Can. J. Plant Pathol. 21:276-283.

CRAAQ. 2013. Fraisier: Guide des traitements phytosanitaires 2013. Publication no. PPTF0113-01PDF. Centre de référence en agriculture et agroalimentaire du Québec, Quebec City, QC, Canada.

Dale, J. L., and Fulton, J. P. 1957. Severe loss from strawberry leaf spot in Arkansas in 1957. Plant Dis. Rep. 41:681-682.

Delhomez, N., Carisse, O., Lareau, M., and Khanizadeh, S. 1995. Susceptibility of strawberry cultivars and advanced selections to leaf spot caused by Mycosphaerella fragariae. HortScience 30:592-595.
Dudley, W. R. 1889. On the strawberry leaf-blight. Cornell Univ. Agr. Exp. Stn. Bull. 14:171-183.

Elliott, V. J. 1988. Response models for conidiospore germination and germ tube elongation of Mycosphaerella fragariae as influenced by temperature and moisture. Phytopathology 78:645-650.

Fulton, R. H. 1958. Studies on strawberry leaf spot in Michigan. Mich. Exp. Stn. Q. Bull. 40:581-588.

Gossen, B. D., Carisse, O., Kawchuk, L. M., Van Der Heyden, H., and McDonald, M. R. 2014. Recent changes in fungicide use and the fungicide insensitivity of plant pathogens in Canada. Can. J. Plant Pathol. 36:327-340.

Janick, J., and Williams, E. B. 1959. Resistance of strawberry varieties and selections to leaf spot and scorch. Plant Dis. Rep. 43:413-415.

Maas, J. L., ed. 1987. Compendium of Strawberry Diseases. APS Press, St. Paul, $\mathrm{MN}$.

Madden, L. V., Hughes, G., and van den Bosch, F. 2007. The Study of Plant Disease Epidemics. APS Press, St. Paul, MN.

Marcoux, A. 1996. Effet de la tache commune sur la photosynthèse et les rendements du fraisier. M.Sc. thesis, Université Laval, Quebec City, QC, Canada.

Nemec, S. 1969. Determination of leaf spot races in southern Illinois strawberry plantings. Plant Dis. Rep. 53:94-97.

Nemec, S. 1971. Studies on resistance of strawberry varieties and selections to Mycosphaerella fragariae in southern Illinois. Plant Dis. Rep. 55:573-576.

Nemec, S. 1972. Temperature effects on Mycosphaerella fragariae and strawberry leaf spot development. Plant Dis. Rep. 56:345-348.

Nutter, F. W., Jr., Teng, P. S., and Royer, M. H. 1993. Terms and concepts for yield, crop loss, and disease thresholds. Plant Dis. 77:211-215.

OMAFRA. 2016. Guide to Fruit Production 2016-2017. Publication 360. Ontario Ministry of Agriculture, Food and Rural Affairs, Toronto.

Paulus, A. O. 1990. Fungal diseases of strawberry. HortScience 25:885-889.

Plakidas, A. G. 1934. The mode of infection of Diplocarpon earliana and Mycosphaerella fragariae. Phytopathology 24:620-634.

Plakidas, A. G. 1965. Strawberry Diseases. Louisiana State University Press, Baton Rouge.

Plouffe, D., Bourgeois, G., Beaudry, N., Chouinard, G., and Choquette, D. 2014 CIPRA-Computer Centre for Agricultural Pest Forecasting: Crop Guide. Tech. Bull. A42-119/2013E-PDF. Online publication. Agriculture and AgriFood Canada. http://www.publications.gc.ca/pub?id=9.698631\&sl=0

Schwartz, M. D. 2013. Phenology: An Integrative Environmental Science. Springer Science+Business Media, Berlin, Germany.

Trealease, W. 1885. The spot disease of strawberry leaves (Ramularia tulasnei, Sacc.). Wisc. Agr. Exp. Stn. Annu. Rep. 2:47-58.

Tulasne, R. L., and Tulasne, C. 1863. Stigmatea fragariae. Selecta fungorum Carpologia 2:86.

Turechek, W. W., and Madden, L. V. 2000. Analysis of the association between the incidence of two spatially aggregated foliar diseases of strawberry. Phytopathology 90:157-170.

Weisberg, S. 2014. Applied Linear Regression, 4th Ed. Wiley, Hoboken, NJ.

Wilhelm, S., and Nelson, R. D. 1980. Fungal diseases of strawberry plant. Pages 245-292 in: The Strawberry: Cultivars to Marketing. N. C. Childers, ed. Horticultural Publication, Gainesville, FL. 